\title{
The cognitive neuropsychiatry of Tourette syndrome
}

\author{
Andrea E. CAVANNA ${ }^{1,2,3^{*}}$, Christos GANOS ${ }^{4}$, Andreas HARTMANN ${ }^{5,6,7}$, Davide \\ MARTINO $^{8}$, Tamara PRINGSHEIM ${ }^{9}$, Stefano SERI ${ }^{3}$
}

${ }^{1}$ Department of Neuropsychiatry, BSMHFT and University of Birmingham, Birmingham, United Kingdom

${ }^{2}$ Sobell Department of Motor Neuroscience and Movement Disorders, Institute of Neurology and University College London, London,

United Kingdom

${ }^{3}$ School of Life and Health Sciences, Aston Brain Centre, Aston University, Birmingham, United Kingdom

${ }^{4}$ Department of Neurology, Charité, University Medicine Berlin, Germany

${ }^{5}$ French Reference Centre for Gilles de la Tourette Syndrome, Groupe Hospitalier Pitié-Salpêtrière, Paris, France

${ }^{6}$ Sorbonne Universités, UPMC Université Paris 06, UMR S 1127, CNRS UMR 7225, ICM, Paris, France

${ }^{7}$ Assistance Publique-Hôpitaux de Paris, Department of Neurology, Groupe Hospitalier Pitié-Salpêtrière, Paris, France

${ }^{8}$ Department of Clinical Neurosciences, Cumming School of Medicine, University of Calgary and Hotchkiss Brain Institute, Calgary, Canada

${ }^{9}$ Department of Clinical Neurosciences, Psychiatry, Pediatrics and Community Health Sciences, University of Calgary, Calgary, Canada

\author{
*Correspondence: \\ Prof Andrea E. Cavanna, MD PhD FRCP FANPA SFHEA \\ Department of Neuropsychiatry \\ National Centre for Mental Health \\ 25 Vincent Drive \\ Birmingham B15 2FG \\ United Kingdom \\ Email: a.e.cavanna@bham.ac.uk
}




\section{Abstract}

Introduction. Converging evidence from both clinical and experimental studies has shown that Tourette syndrome (TS) is not a unitary condition, but a cluster of multiple phenotypes, which encompass both tics and specific behavioural and cognitive symptoms (mainly attention-deficit and hyperactivity disorder and obsessive-compulsive disorder).

Methods. We conducted a narrative review of the recent literature on the cognitive neuropsychiatry of TS.

Results. Although clinical research has shown that TS is not associated with cognitive deficits per se, the findings of recent studies have suggested the presence of subtle alterations in specific cognitive functions. A promising line of research on imitative behaviour could provide a common background for the alterations in executive control and social cognition observed in TS. Two different (but not mutually exclusive) neurocognitive theories have recently suggested that TS could originate from altered perception-action binding and social decision-making dysfunction, respectively.

Conclusions. Since the presence of behavioural co-morbidities influences individualised treatment approaches, it is likely that a more precise characterisation of TS phenotypes, including cognitive aspects, will result in improved levels of care for patients with tic disorders.

Keywords. Tourette syndrome; tics; cognitive neuropsychiatry; perception-action binding; social decision-making; premonitory urges; behaviour; obsessive-compulsive disorder; attention-deficit and hyperactivity disorder; health-related quality of life. 


\section{Introduction}

Tourette syndrome (TS) is a neurodevelopmental condition characterised by multiple motor and vocal tics (American Psychiatric Association, 2013). The majority of patients with TS report specific behavioural symptoms, which can affect their health-related quality of life to a greater extent than tics themselves (Cavanna \& Seri, 2013; Robertson et al., 2017). The exact pathophysiology of TS is still elusive: as a result, treatment approaches are often empirical. It has recently emerged that one of the reasons for this impasse is the multifaceted nature of TS, a condition presenting with heterogeneous phenotypes in terms of both tics and behavioural symptoms. Moreover, cognitive neuropsychiatry studies have shown that patients with TS can have specific cognitive alterations, with implications for the phenotypic characterisation of TS, its underlying pathophysiology, and novel therapeutic strategies. Recent advances have led to a better characterisation of neural networks underlying both the subjective 'urge to tic' and tic expression (Cavanna, Black, Hallett, \& Voon, 2017) and to the development of evidence-based treatment interventions, epitomised in the guidelines recently published in the United States (Pringsheim et al., 2019a, 2019b). This review article presents the state-of-the-art on TS research, with focus on recent findings about behavioural and cognitive phenotypes, as well as their clinical implications. 


\section{Tourette syndrome as a cluster of multiple clinical phenotypes}

\section{Clinical characteristics and epidemiology of tics}

Tic disorders are the most common movement disorders in childhood (Cubo, 2012; Ganos \& Martino, 2015). Tic severity can range from mild tics, which often go unnoticed, to forceful movements and loud noises, potentially causing both physical and psychological distress (Table 1). Coprolalia has been reported in a minority of patients with TS (up to $30 \%$ in specialist clinics and $10-15 \%$ in the community) and does not feature among current diagnostic criteria for tic disorders (Eddy \& Cavanna, 2013a). Tics are characterised by a fluctuating course and are often suggestible or inducible (Cavanna \& Seri, 2013; Finis et al., 2012; Robertson et al., 2017). Tic-exacerbating factors include specific sensory stimuli such as stress, excitement, and tiredness. Most patients can voluntarily suppress tics for varying lengths of time, and higher satisfaction with tic control has been shown to positively impact health-related quality of life (Matsuda, Kono, Nonaka, Fujio, \& Kano, 2015).

\section{[PLEASE INSERT TABLE 1 HERE]}

Of note, motor and vocal tics share the same underlying brain mechanisms and are best viewed along a clinical and pathophysiological continuum, although animal models of TS have shown that motor and vocal tics have distinct (but overlapping to some extent) neural circuitries. Specifically, cerebro-basal ganglia-cerebellar networks have been shown to underlie motor tics (McCairn, Iriki, \& Isoda, 2013), whereas a primary role for the nucleus accumbens and related limbic network has been identified in vocal tics (McCairn et al., 2016). TS symptoms usually begin with simple motor tics (most commonly eye blinking), followed by other simple motor tics and more complex tics following a rostro-caudal 
distribution (Martino, Cavanna, Robertson, \& Orth, 2012) (Table 2). Vocal tics tend to develop after the onset of motor tics, usually before the pubertal period (Ganos, Bongert, Asmuss, Martino, Haggard, \& Münchau, 2015). Little is known about factors affecting prognosis in patients with TS, in terms of both tic severity and health-related quality of life (Cavanna, David, Robertson, \& Orth, 2012; Groth, Skov, Lange, \& Debes, 2019; Hassan \& Cavanna, 2012). Although large longitudinal studies have shown a considerable agedependent decline in tic severity from childhood to adulthood (e.g. Groth, Mol Debes, Rask, Lange, \& Skov, 2017), there is evidence that adult patients may believe they are ticfree while still having some tics (Pappert, Goetz, Louis, Blasucci, \& Leurgans, 2003).

\section{[PLEASE INSERT TABLE 2 HERE]}

The key diagnostic features of tic disorders are coded in the most recent edition of the

Diagnostic and Statistical Manual for Mental Disorders (DSM-5) (American Psychiatric Association, 2013; Müller-Vahl, Sambrani, \& Jakubovski, 2019) (Table 3).

\section{[PLEASE INSERT TABLE 3 HERE]}

Prevalence figures for TS in the general paediatric population range between $0.3 \%$ and 1\% (Knight, Steeves, Day, Lowerison, Jette, \& Pringsheim, 2012; Scharf, Miller, Gauvin, Alabiso, Mathews, \& Ben-Shlomo, 2015). Tics as isolated symptoms potentially affect around $5 \%$ of the general population, although prevalence figures show a wide variability (Cubo, 2012; Ong, Mordekar, \& Seal, 2016). The prevalence of all tic disorders in paediatric age approaches $3 \%$, whereas in adults tics appear to be less common (Knight, Steeves, Day, Lowerison, Jette, \& Pringsheim, 2012). The average age at tic onset is 5-7 years, and males are three-to-four times more commonly affected than females (Cavanna 
\& Seri, 2013; Robertson et al., 2017). There appears to be a decreasing prevalence risk ratio for gender in adults compared to children, as well as greater tic-related disability and more co-morbidities in female patients (Lichter \& Finnegan, 2015; Yang et al., 2016).

\section{Aetiology and pathophysiology of tics}

Over the last few years, clinical studies using statistical techniques including principal component factor analysis and hierarchical cluster analysis have started to dissect the phenotypic heterogeneity of TS (Cavanna, 2018a, 2018b). From a clinical point of view, TS has been classified into three subgroups of patients with different degrees of complexity and care needs: 'pure' TS (patients with motor and vocal tics only), 'full-blown' TS (patients with additional copro/echo/paliphenomena, forced touching, non-obscene socially inappropriate behaviours, or other tic-related symptoms), and TS 'plus' (patients diagnosed with co-morbid psychiatric disorders) (Cavanna \& Rickards, 2013; Eapen \& Robertson, 2015). The high clinical heterogeneity of TS suggests an equally complex aetiology. A still unclear genetic background further modified by non-genetic factors, possibly including pre- and peri-natal difficulties as well as post-infectious autoimmunity, has been proposed as a likely aetiological framework for TS (Paschou, 2013). Converging findings from both twin and family studies have shown that TS is one of the most heritable, non-Mendelian neurodevelopmental disorders, with a population-based heritability estimate of 0.77 (Pauls, Fernandez, Mathews, State, \& Scharf, 2014). Although to date no definitive TS-associated risk genes of major effect have been identified, recent international collaborative studies have provided evidence for the first robust genetic associations to TS (Paschou, 2013; Willsey et al., 2017). The characterisation of TS phenotypes based on patterns of co-occurrence of tics, cognitive and behavioural endophenotypes is a fundamental prerequisite for the establishment of more precise phenotype-genotype correlations (Darrow et al., 2017; Huisman-van Dijk, van de Schoot, 
Rijkeboer, Mathews, \& Cath, 2016). In terms of environmental factors, the potential role of both pre-natal and peri-natal events in the aetiology of TS has been investigated by recent epidemiological studies (Abdulkadir et al., 2016). The identification of maternal factors that might increase the risk of tic disorders in offspring, including chronic anxiety, alcohol and cannabis use, smoking and less-than-adequate weight gain during pregnancy, is of potential clinical relevance and requires further confirmation across different patients populations (Browne et al., 2016). The hypothesis that TS could belong to a group of conditions called 'paediatric autoimmune neuropsychiatric disorders associated with streptococcal infections' (PANDAS) is still being investigated, although the possible aetiological role of autoimmune mechanisms in a subgroup of patients with TS has recently been questioned (Martino, Zis, \& Buttiglione, 2015).

The majority of patients with TS report that their tics are preceded/accompanied by distressing sensory experiences that are commonly referred to as 'premonitory urges' to tic (Brandt et al., 2016; Crossley \& Cavanna, 2013; Eddy \& Cavanna, 2014a; Ganos et al., 2015). Recent neuroimaging findings have shown activation patterns within extra-motor areas (including insula and cingulate cortex) concomitant to premonitory urges, suggesting their possible involvement in tic generation (Cavanna, Black, Hallett, \& Voon, 2017). Moreover, heterogeneous pathophysiological pathways, mainly involving the neurotransmitter dopamine, might be responsible for the clinical expression of different TS phenotypes. At least three parallel, interacting cortico-striato-thalamo-cortical circuits, linking specific frontal regions to subcortical nuclei (including the basal ganglia and thalamus) are thought to be involved in the pathophysiology of TS. These have been referred to as the habitual behavioural circuit, the goal-directed circuit, and the emotionrelated limbic circuit, which is key to the behavioural aspects of TS, as it connects the basal ganglia with the limbic system via inputs from the hippocampus, amygdala, prefrontal cortex, and anterior cingulate gyrus to the ventral striatum (nucleus accumbens) 
(Singer, 2016). Specifically, changes of both pallidal and striatal neurons have been described in post-mortem TS brain specimens (Kalanithi et al., 2005; Kataoka et al., 2010), raising the possibility that these changes could be due to a neuronal migration defect during brain development. Despite convergent evidence for basal ganglia circuit abnormalities in TS, there is no obvious way to connect basal ganglia circuit abnormalities with several salient features of TS, suggesting that alterations in previously unexamined regions may be important in the pathophysiology of TS.

\section{The behavioural spectrum of Tourette syndrome}

The high prevalence of co-morbid behavioural conditions, especially ADHD and OCD, can pose considerable challenges in the diagnostic and therapeutic pathways of patients with TS (Khalifa \& von Knorring, 2006). ADHD is the most common co-morbid behavioural problem in young patients with TS seeking medical attention: reported prevalence rates range from $38 \%$ (in community settings) to over 60\% (in specialist clinics) (Cavanna \& Rickards, 2013), with male patients being at a significantly higher risk (Hirschtritt et al., 2015). ADHD symptoms first present at 3-5 years of age in the majority of patients, with three major clinical phenotypes (inattentive, hyperactive-impulsive, and combined ADHD). Although ADHD is known to improve to a significant extent by adulthood, its persistence through key developmental stages has far-reaching consequences, including on executive functions (Termine et al., 2016).

Patients with TS often complain of distressing and time-consuming repetitive behaviours (compulsions) and/or thoughts (obsessions). Prevalence rates of co-morbid OCD in patients with TS range from 11 to $66 \%$, although it has been estimated that the prevalence of sub-threshold obsessive-compulsive behaviours could be considerably higher (Eddy \& Cavanna, 2014b; Hirschtritt et al., 2015; Martino et al., 2017). Consistent findings have shown that patients with tics tend to report specific obsessive-compulsive symptoms, 
which are phenomenologically different from the symptoms reported by patients who have OCD without tics. In patients with TS there is a significantly higher prevalence of concerns for symmetry, evening-up behaviours, obsessional counting (arithmomania), ordering, and 'just right' perceptions, whereas patients with uncomplicated OCD have a higher rate of concerns for contamination, as well as cleaning/washing rituals (Eddy \& Cavanna, 2014b). Tic-related OCD was included in the DSM-5 as a subtype of OCD in patients who have a current or past history of a tic disorder. Male preponderance and earlier age at onset compared to OCD without tics are further clinical features which indicate that tic-related OCD could be intrinsic to TS (American Psychiatric Association, 2013), with implications for both the diagnosis and the clinical management of complex cases.

Patients with TS have been shown to be prone to impulsivity and anger outbursts, that can be captured by the diagnostic criteria of intermittent explosive disorder (Budman, Rosen, \& Shad, 2015; Martino et al., 2017). The chronic presence of tics increases the risk of developing depression and anxiety (Cuenca et al., 2015; Piedad \& Cavanna, 2016), with social stigma, behavioural co-morbidities, and adverse effects of anti-tic medications playing contributory roles. The neurodevelopmental trajectory of TS can overlap with autism spectrum disorder, as indicated by co-morbidity rates of up to $25 \%$ (Huisman-van Dijk, van de Schoot, Rijkeboer, Mathews, \& Cath, 2016; Martino et al., 2017). Finally, the association between TS and specific personality disorders/traits has been suggested by preliminary findings (Trillini \& Müller-Vahl, 2015). 


\section{Neurocognitive aspects of Tourette syndrome}

\section{Executive function and inhibitory control}

The cognitive neuropsychiatry of TS has been the subject of intensive research over recent years. Neuropsychological studies have mainly focused on the possible effects of fronto-striatal dysfunction on a range of cognitive domains, including attention, memory, language, executive functions, motor and visuomotor functions, among others. Two exhaustive reviews of the neuropsychological aspects of TS have been published in the last decade (Eddy et al., 2009; Morand-Beaulieu et al., 2017b). Although most findings have been inconclusive, the neurocognitive domains of executive functions and social cognition appear to be the most promising in terms of improving our characterisation of TS endophenotypes.

Recent data seem to confirm that alterations in executive functions in TS appear to be limited to selected domains, rather than widespread. A fruitful line of research focused on the presence of deficits regarding inhibitory control, while impairments in planning and decision-making were reported considerably less frequently. A number of studies explored the possibility of response inhibition deficits in patients with TS, with conflicting results (e.g. Abramovitch et al., 2017; Yaniv et al., 2018). A recent meta-analysis on the puzzling question of inhibitory control in TS revealed a small-to-medium effect in favor of inhibitory deficits in this patient population. Specifically, there was evidence of larger inhibitory deficits in patients with TS and co-morbid ADHD, although these deficits were also present in patients with 'pure' TS (Morand-Beaulieu et al., 2017a). Interestingly, this deficit was most prominent in verbal responses, was associated with measures of tic severity, and was larger in studies that included medicated patients.

TS frequently involves complex tics with social significance, including imitation or socially inappropriate behaviour. In addition to echopraxia, simple tics can be triggered by 
watching tics or single voluntary movements. A controlled study exploring every-day perspective taking and empathic tendencies showed that patients with TS have a different interpersonal reactivity profile compared to controls (Eddy, Macerollo, Martino, \& Cavanna, 2015). More broadly, it has been suggested that differing behavioural effects of movement observation in TS might reflect altered activation of an action observation-execution matching system. According to the results of a behavioural study of imitation, to avoid unwanted movements patients with TS might have to inhibit motor activation automatically induced by movement observation (Jonas et al., 2010). There is evidence that this automatic imitation of movements should be ascribed to highly overlearned behavior that can be triggered without interference by external, incompatible movement stimuli, rather than failure in top-down inhibition of imitative response tendencies (Brandt, Patalay, Bäumer, Brass, \& Münchau, 2016). Both children and adult patients with TS appear to compensate for their enhanced ability to inhibit automatic imitation tendencies by an overall slowing in response times (Brandt et al., 2019). The promising line of research on imitative behaviour and automatic imitation could provide a common background for the alterations in executive control and social cognition observed in TS.

\section{Social cognition}

Social cognition refers to a set of cognitive processes that allow for adequate social adjustment and functioning, ranging from basic social functions (e.g. face recognition, emotion perception) to higher-order processes (e.g. social reasoning, empathy). These processes are thought to be mediated by complex neural networks involving the basal ganglia and frontal lobes, as well as more specialised areas such as the fusiform gyrus. In comparison with other neuropsychological domains, social cognition in TS has traditionally received relatively little attention, however interesting findings have started to emerge in the last few years (Eddy \& Cavanna, 2013b). Overall, early findings have provided 
evidence for alterations in social reasoning and social decision-making (investigated through the socioeconomic Ultimatum Game) (Eddy, Mitchell, Beck, Cavanna, \& Rickards, 2011; Hinterbuchinger, Kaltenboeck, Baumgartner, Mossaheb, \& Friedrich, 2018). Specifically, the ability to distinguish mental states relating to the self and other may be impaired in TS, contributing to a range of symptoms, including complex tics (e.g. echophenomena), tic-related compulsive behaviours, and impulsive socially inappropriate behaviours (Channon, Drury, Gafson, Stern, \& Robertson, 2012; Eddy, 2018). Research focusing on theory of mind in patients with TS has shown that hyper-mentalising (a greater tendency to attribute mental states to others) could be an important feature in at least a subgroup of patients with TS (Eddy \& Cavanna, 2013b, 2015). The observed changes in theory of mind could reflect dysfunction in fronto-striatal pathways involving the ventromedial prefrontal cortex (Eddy, Mitchell, Beck, Cavanna, \& Rickards, 2011). Moreover, evidence from recent neuroimaging studies points towards functional changes at the level of the temporo-parietal junction as a key component of the neural correlates of alterations in social cognition in TS (Eddy, Cavanna, \& Hansen, 2017).

\section{Altered perception-action binding and social decision-making dysfunction}

The complex relationship between tics, premonitory urges, and cognitive alterations suggests increased internal monitoring (Ganos et al., 2015) as well as abnormal sense of agency (Delorme et al., 2016). It has been proposed that TS could be conceptualised within a theoretical cognitive framework integrating perceptual, cognitive, and motor aspects of action, referred to as the theory of event coding (Hommel, 2004). The neurocognitive theory that increased perception-action binding in TS is associated with a propensity to generate a surplus of action implies that tics do not categorically differ from other actions, but result from quantitative alterations in the strength of perception-action binding (Beste \& Münchau, 2018). Specifically, it is possible that dopaminergic 
hyperactivity in TS increases learning and habit-formation processes, leading to the emergence of tics as a surplus phenomenon (Buse, Schoenefeld, Münchau, \& Roessner, 2013). The role played by altered perception-action integration in the pathophysiology of TS was tested in the context of inhibitory control in a controlled behavioural study on adolescents with TS, combined with event-related potential recordings, electroencephalographic data decomposition, and source localisation (Petruo et al., 2019). Stimulus-action inhibition binding was found to be stronger in patients with TS compared to healthy controls and to affect inhibitory control, supporting the hypothesis that TS might be a disorder of purposeful actions. Moreover, the neurophysiological data showed that this was related to mechanisms mediating between stimulus evaluation and response selection, i.e. perception-action binding processes in the right inferior parietal cortex. The effect of a standardised Comprehensive Behavior Intervention for Tics on perceptionaction binding was tested in an inhibitory control paradigm on adolescents with TS and healthy controls (Petruo, Bodmer, Bluschke, Münchau, Roessner, \& Beste, 2020). The behavioural intervention was found to specifically affect inhibitory control in a condition where reconfigurations of perception-action bindings are necessary to perform inhibitory control. These results suggested that the Comprehensive Behavior Intervention for Tics could reduce increased binding between perception and action in TS and thereby increase the ability to perform response inhibition. In addition to explaining the existence of a large spectrum of tics from hardly noticeable twitches to severe jerks, the perception-action binding model could pave the way to new treatments, including those aiming at unbinding event files (neural codes linking perceptual stimulus and features that specify an action), and thus improving tics.

It has recently been suggested that TS may be a disorder of social communication resulting from developmental abnormalities at several levels of the social decision-making network, a neural system with two functionally complementary limbs: the basal ganglia 
component responsible for evaluation of socially relevant stimuli and actions, and the social behaviour network component responsible for the performance of social acts (Albin, 2018). Interestingly, some nuclei of the social behaviour network are sexually dimorphic, and the social behaviour network function is strongly modulated by gonadal steroids. Recent studies indicate that the social behaviour network meshes with the basal ganglia to form the larger social decision-making network (O'Connell \& Hofmann, 2011). The social decision-making network concept overlaps significantly with Holstege's model of an emotional motor system mediating socially relevant facial movements (Holstege, 2002) and phonations (Holstege \& Subramanian, 2016). Dopaminergic signalling within the basal ganglia component of the social decision-making network may regulate social act motivation with the social behaviour network component responsible for act expression. Developmental social decision-making network abnormalities may account for several characteristic features of TS, such as its natural history, male predominance, the characteristic distribution and stereotyped quality of tics, the modulation of tic expression by task engagement, the role of the basal ganglia, and the recent identification of a heritable TS subphenotype characterised by social disinhibition (Hirschtritt et al., 2016). The social decision-making network hypothesis suggests novel therapeutic targets. Conceptualising TS as a disorder of social communication manifesting primarily as abnormal involuntary movements suggests the possibility that the amygdala nuclei, as key centres involved in social behaviours, and the periaqueductal grey, as critical output node of the social decision-making network regulating motor pathways, could become attractive intervention targets.

Overall, both the theory of perception-action binding (Beste \& Münchau, 2018) and the social decision-making network dysfunction hypothesis (Albin, 2018, 2019) are neurocognitive models that suggest new avenues for research in TS and new potential therapeutic targets. A number of clinical features of TS are explicitly accounted for by the 
altered perception-action binding theory and the social decision-making dysfunction theory, two models that are not mutually incompatible (Table 4).

\section{[PLEASE INSERT TABLE 4 HERE]}

Since motor behaviours result from a complex integration between cortical and subcortical areas, underlying the motor, cognitive, and motivational aspects of movement, there might be a role in targeting both motor and cognitive aspects in the treatment of basal ganglia disorders. For example, there is growing evidence for the role of cognitive engagement in motor rehabilitation in other movement disorders in which cognitive dysfunctions affect the motor behaviour, such as Parkinson disease (Ferrazzoli et al., 2018). 


\section{Conclusions and future directions}

The current renaissance of behavioural neurology as a clinical discipline has outlined promising avenues to further our understanding of TS. The most important 'paradigm shift' in our current understanding of TS is arguably the concept that TS is not a unitary condition, as originally believed, but a cluster of multiple behavioural and cognitive phenotypes. The increased focus on the behavioural and cognitive aspects of TS has led to a better understanding of patients' clinical phenotypes and their individual care needs. A number of open questions need to be addressed by future research. The establishment of more precise phenotype-genotype correlations and the validation of animal models of tics could help elucidate the complex interplay between genetic and environmental aetiological factors. The identification of biomarkers or endophenotypes for specific behavioural and cognitive phenotypes of TS and their possible associations with altered neurodevelopmental trajectories will require studies on large and well characterised cohorts of patients. A promising line of research on imitative behaviour and automatic imitation could provide a common background for the alterations in executive control and social cognition observed in TS. Two different (but not mutually exclusive) neurocognitive theories have recently suggested that TS could originate from altered perception-action binding and social decision-making dysfunction, respectively. Finally, the shift of research focus from motor outputs to sensory urges and aspects of social cognition could unravel unexpected pathophysiological mechanisms and facilitate the development of targeted treatment interventions to further improve quality of care. 


\section{Declaration of interests}

None of the authors has stocks, equity, a contract of employment, or a named position on a company board that will benefit from content in the present review, for which there was no funding source. AEC drafted the manuscript and all co-authors provided critical comment and writing input into the final version of the manuscript. 


\section{References}

- Abdulkadir, M., Tischfield, J.A., King, R.A., Fernandez, T.V., Brown, L.W., Cheon, K.A., ..., Dietrich A. (2016). Pre- and perinatal complications in relation to Tourette syndrome and co-occurring obsessive-compulsive disorder and attention-deficit/hyperactivity disorder. Journal of Psychiatric Research, 82, 126-135.

- Abramovitch, A., Hallion, L.S., Reese, H.E., Woods, D.W., Peterson, A., Walkup, J.T., ..., Wilhelm, S. (2017). Neurocognitive predictors of treatment response to randomized treatment in adults with tic disorders. Progress in Neuro-Psychopharmacology and Biological Psychiatry, 74, 9-14.

- Albin, R.L. (2018). Tourette syndrome: A disorder of the social decision-making network. Brain, 141, 332-347.

- Albin, R.L. (2019). Tourette syndrome as a disorder of the social decision-making network. Frontiers in Psychiatry, 10, 742.

- American Psychiatric Association. (2013). Diagnostic and Statistical Manual of Mental Disorders. 5th ed. Arlington, VA: American Psychiatric Publishing.

- Beste, C, \& Münchau, A. (2018). Tics and Tourette syndrome: Surplus of actions rather than disorder? Movement Disorders, 33, 238-242.

- Brandt, V.C., Beck, C., Sajin, V., Baaske, M.K., Bäumer, T., Beste, C., .., Münchau, A. (2016). Temporal relationship between premonitory urges and tics in Gilles de la Tourette syndrome. Cortex, 77, 24-37.

- Brandt, V.C., Moczydlowski, A., Jonas, M., Boelmans, K., Bäumer, T., Brass, M., \& Münchau, A. (2019). Imitation inhibition in children with Tourette syndrome. Journal of Neuropsychology, 13, 82-95. 
- Brandt, V.C., Patalay, P., Bäumer, T., Brass, M., \& Münchau, A. (2016). Tics as a model of over-learned behavior-imitation and inhibition of facial tics. Movement Disorders, 31, 1155-1162.

- Browne, H.A., Modabbernia, A., Buxbaum, J.D., Hansen, S.N., Schendel, D.E., Parner, E.T., ..., Grice, D.E. (2016). Prenatal maternal smoking and increased risk for Tourette syndrome and chronic tic disorder. Journal of the American Academy of Child and Adolescent Psychiatry, 55, 784-791.

- Budman, C.L., Rosen, M., \& Shad, S. (2015). Fits, tantrums, and rages in TS and related disorders. Current Developmental Disorders Reports, 2, 273-284.

- Buse, J., Schoenefeld, K., Münchau, A., \& Roessner, V. (2013). Neuromodulation in Tourette syndrome: Dopamine and beyond. Neuroscience and Biobehavioral Review, 37, 1069-1084.

- Cavanna, A.E. (2018a). Gilles de la Tourette syndrome as a paradigmatic neuropsychiatric disorder. CNS Spectrums, 23, 213-218.

- Cavanna, A.E. (2018b). The neuropsychiatry of Gilles de la Tourette syndrome: The état de l'art. Revue Neurologique, 174, 621-627.

- Cavanna, A.E., \& Rickards, H.E. (2013). The psychopathological spectrum of Gilles de la Tourette syndrome. Neuroscience and Biobehavioral Reviews, 37, 1008-1015.

- Cavanna, A.E., \& Seri, S. (2013). Tourette's syndrome. British Medical Journal, 347, f4964.

- Cavanna, A.E., Black, K.J., Hallett, M., \& Voon, V. (2017). Neurobiology of the premonitory urge in Tourette's syndrome: Pathophysiology and treatment implications. Journal of Neuropsychiatry and Clinical Neurosciences, 29, 95-104. 
- Cavanna, A.E., David, K., Robertson, M.M., \& Orth, M. (2012). Predictors during childhood of future health-related quality of life in adults with Gilles de la Tourette syndrome. European Journal of Paediatric Neurology, 16, 605-612.

- Channon, S., Drury, H., Gafson, L., Stern, J., \& Robertson, M.M. (2012). Judgements of social inappropriateness in adults with Tourette's syndrome. Cognitive Neuropsychiatry, 17, 246-261.

- Crossley, E., Cavanna, A.E. (2013). Sensory phenomena: Clinical correlates and impact on quality of life in adult patients with Tourette syndrome. Psychiatry Research, 209, 705-710.

- Cubo, E. (2012). Review of prevalence studies of tic disorders: Methodological caveats. Tremor and Other Hyperkinetic Movements, 2, tre-02-61-349-1.

- Cuenca, J., Glazebrook, C., Kendall, T., Hedderly, T., Heyman, I., Jackson, G., ..., Hollis, C. (2015). Perceptions of treatment for tics among young people with Tourette syndrome and their parents: A mixed methods study. BMC Psychiatry, 15, 46.

- Darrow, S.M., Hirschtritt, M.E., Davis, L.K., Illmann, C., Osiecki, L., Grados, M., ..., Tourette Syndrome Association International Consortium for Genetics. (2017). Identification of two heritable cross-disorder endophenotypes for Tourette syndrome. American Journal of Psychiatry, 174, 387-396.

- Delorme, C., Salvador, A., Voon, V., Roze, E., Vidailhet, M., Hartmann, A., \& Worbe, Y. (2016). Illusion of agency in patients with Gilles de la Tourette syndrome. Cortex, 77, 132-140.

- Eapen, V., \& Robertson, M.M. (2015). Are there distinct subtypes in Tourette syndrome? Pure-Tourette syndrome versus Tourette syndrome-plus, and simple versus complex tics. Neuropsychiatric Disease and Treatment, 1, 1431-1436. 
- Eddy, C.M. (2018). Social cognition and self-other distinctions in neuropsychiatry: Insights from schizophrenia and Tourette syndrome. Progress in Neuropsychopharmacology and Biological Psychiatry, 82, 69-85.

- Eddy, C.M, \& Cavanna, A.E. (2013a). 'It's a curse!': Coprolalia in Tourette syndrome. European Journal of Neurology, 20, 1467-1470.

- Eddy, C.M., \& Cavanna, A.E. (2013b). Altered social cognition in Tourette syndrome: Nature and implications. Behavioural Neurology, 27, 15-22.

- Eddy, C.M., \& Cavanna, A.E. (2014a). Premonitory urges in adults with complicated and uncomplicated Tourette syndrome. Behavior Modification, 38, 264-275.

- Eddy, C.M., \& Cavanna, A.E. (2014b). Tourette syndrome and obsessive compulsive disorder: Compulsivity along the continuum. Journal of Obsessive-Compulsive and Related Disorders, 3, 363-371.

- Eddy, C.M., \& Cavanna, A.E. (2015). Triangles, tricks and tics: Hyper-mentalizing in response to animated shapes in Tourette syndrome. Cortex, 71, 68-75.

- Eddy, C.M., Cavanna, A.E., \& Hansen, P.C. (2017). Empathy and aversion: The neural signature of mentalizing in Tourette syndrome. Psychological Medicine, 47, 507-517.

- Eddy, C.M., Macerollo, A., Martino, D., \& Cavanna, A.E. (2015). Interpersonal reactivity differences in Tourette syndrome. Psychiatry Research, 228, 932-935.

- Eddy, C.M., Mitchell, I.J., Beck, S.R., Cavanna, A.E., \& Rickards, H. (2011). Social reasoning in Tourette syndrome. Cognitive Neuropsychiatry, 16, 326-347.

- Eddy, C.M., Rizzo, R., \& Cavanna, A.E. (2009). Neuropsychological aspects of Tourette syndrome: A review. Journal of Psychosomatic Research, 67, 503-513.

- Ferrazzoli, D., Ortelli, P., Madeo, G., Giladi, N., Petzinger, G.M., \& Frazzitta, G. (2018). Basal ganglia and beyond: The interplay between motor and cognitive aspects in 
Parkinson's disease rehabilitation. Neuroscience and Biobehavioral Reviews, 90, 294308.

- Finis, J., Moczydlowski, A., Pollok, B., Biermann-Ruben, K., Thomalla, G., Heil, M., ..., Münchau, A. (2012). Echoes from childhood: Imitation in Gilles de la Tourette syndrome. Movement Disorders, 27, 562-565.

- Ganos, C., \& Martino, D. (2015). Tics and Tourette syndrome. Neurologic Clinics, 33, 115-136.

- Ganos, C., Bongert, J., Asmuss, L., Martino, D., Haggard, P., \& Münchau, A. (2015). The somatotopy of tic inhibition: Where and how much? Movement Disorders, 30, 1184-1189.

- Ganos, C., Garrido, A., Navalpotro-Gómez, I., Ricciardi, L., Martino, D., Edwards, M.J., ..., Bhatia, K.P. (2015). Premonitory urge to tic in Tourette's is associated with interoceptive awareness. Movement Disorders, 30, 1198-1202.

- Groth, C., Mol Debes, N., Rask, C.U., Lange, T., \& Skov, L. (2017). Course of Tourette syndrome and comorbidities in a large prospective clinical study. Journal of the American Academy of Child and Adolescent Psychiatry, 56, 304-312.

- Groth, C., Skov, L., Lange, T., \& Debes, N.M. (2019). Predictors of the clinical course of Tourette syndrome: A longitudinal study. Journal of Child Neurology, 34, 913-921.

- Hassan, N., \& Cavanna, A.E. (2012). The prognosis of Tourette syndrome: Implications for clinical practice. Functional Neurology, 27, 23-27.

- Hinterbuchinger, B., Kaltenboeck, A., Baumgartner, J.S., Mossaheb, N., \& Friedrich F. (2018). Do patients with different psychiatric disorders show altered social decisionmaking? A systematic review of ultimatum game experiments in clinical populations. Cognitive Neuropsychiatry, 23:117-141. 
- Hirschtritt ME, Darrow SM, Illmann C, Osiecki L, Grados M, Sandor P., ..., Tourette Syndrome Association International Consortium for Genetics (TSAICG). (2016). Social disinhibition is a heritable subphenotype of tics in Tourette syndrome. Neurology, 87 , 497-504

- Hirschtritt, M.E., Lee, P.C., Pauls, D.L., Dion, Y., Grados, M.A., Illmann, C., ..., Tourette Syndrome Association International Consortium for Genetics. (2015). Lifetime prevalence, age of risk, and genetic relationships of comorbid psychiatric disorders in Tourette syndrome. JAMA Psychiatry, 72, 325-333.

- Holstege, G. (2002). Emotional innervation of facial musculature. Movement Disorders, 17(Suppl), S12-16.

- Holstege, G., Subramanian, H.H. (2016). Two different motor systems are needed to generate human speech. Journal of Comparative Neurology, 524, 1558-1577.

- Hommel, B. (2004). Event files: Feature binding in and across perception and action. Trends in Cognitive Sciences, 8, 494-500.

- Huisman-van Dijk, H.M., van de Schoot, R., Rijkeboer, M.M., Mathews, C.A., \& Cath, D.C. (2016). The relationship between tics, OC, ADHD and autism symptoms: A crossdisorder symptom analysis in Gilles de la Tourette syndrome patients and familymembers. Psychiatry Research, 237, 138-146.

- Jonas, M., Thomalla, G., Biermann-Ruben, K., Siebner, H.R., Müller-Vahl, K., Bäumer, T., ..., Münchau, A. (2010). Imitation in patients with Gilles de la Tourette syndrome: A behavioral study. Movement Disorders, 25, 991-999.

- Kataoka, Y., Kalanithi, P.S., Grantz, H., Schwartz, M.L., Saper, C., Leckman, J.F., \& Vaccarino, F.M. (2010). Decreased number of parvalbumin and cholinergic interneurons in the striatum of individuals with Tourette syndrome. Journal of Comparative Neurology, 518, 277-291. 
- Kalanithi, P.S., Zheng, W., Kataoka, Y., DiFiglia, M., Grantz, H., Saper, C.B., ..., Vaccarino, F.M. (2005). Altered parvalbumin-positive neuron distribution in basal ganglia of individuals with Tourette syndrome. Proceedings of the National Academy of Sciences of the United States of America, 102, 13307-13312.

- Khalifa, N., \& von Knorring, A.L. (2006). Psychopathology in a Swedish population of school children with tic disorders. Journal of the American Academy of Child and Adolescent Psychiatry, 45, 1346-1353.

- Knight, T., Steeves, T., Day, L., Lowerison, M., Jette, N., \& Pringsheim, T. (2012). Prevalence of tic disorders: A systematic review and meta-analysis. Pediatric Neurology 47, 77-90.

- Lichter, D., \& Finnegan, S. (2015). Influence of gender on Tourette syndrome beyond adolescence. European Psychiatry, 30, 334-340.

- Martino, D., Cavanna, A.E., Robertson, M.M., \& Orth, M. (2012). Prevalence and phenomenology of eye tics in Gilles de la Tourette syndrome. Journal of Neurology, 259, 2137-2140.

- Martino, D., Ganos, C., \& Pringsheim, T.M. (2017). Tourette syndrome and chronic tic disorders: The clinical spectrum beyond tics. International Review of Neurobiology, $134,1461-1490$.

- Martino, D., Zis, P., \& Buttiglione, M. (2015). The role of immune mechanisms in Tourette syndrome. Brain Research, 1617, 126-143.

- Matsuda, N., Kono, T., Nonaka, M., Fujio, M., \& Kano, Y. (2015). Self-initiated coping with Tourette's syndrome: Effect of tic suppression on QOL. Brain \& Development, 38, 233-241.

- Matthews, C.A., Scharf, J.M., Miller, L.L., Macdonald-Wallis, C., Lawlor, D.A., \& BenShlomo, Y. (2014). Association between pre- and perinatal exposures and Tourette 
syndrome or chronic tic disorder in the ALSPAC cohort. British Journal of Psychiatry, $204,40-45$.

- McCairn, K.W., Iriki, A., \& Isoda, M. (2013). Global dysrhythmia of cerebro-basal ganglia-cerebellar networks underlies motor tics. Journal of Neuroscience, 33, 697708.

- McCairn, K.W., Nagai, Y., Hori, Y., Ninomiya, T., Kikuchi, E., Lee, J.Y., ..., Matsumoto, M. (2016). A primary role for nucleus accumbens and related limbic network in vocal tics. Neuron, 89, 300-307.

- Morand-Beaulieu, S., Grot, S., Lavoie, J., Leclerc, J.B., Luck, D., \& Lavoie, M.E. (2017a). The puzzling question of inhibitory control in Tourette syndrome: A metaanalysis. Neuroscience and Biobehavioral Reviews, 80, 240-262.

- Morand-Beaulieu, S., Leclerc, J.B., Valois, P., Lavoie, M.E., O'Connor, K.P., \& Gauthier, B. (2017b). A review of the neuropsychological dimensions of Tourette syndrome. Brain Sciences, 7(8): pii: E106.

- Müller-Vahl, K.R., Sambrani, T., \& Jakubovski, E. (2019). Tic disorders revisited: Introduction of the term "tic spectrum disorders". European Child and Adolescent Psychiatry, 28, 1129-1135.

- O'Connell, L.A., \& Hofmann, H.A. (2011). The vertebrate mesolimbic reward system and social behavior network: A comparative synthesis. Journal of Comparative Neurology, 519, 3599-3639.

- Ong, M.T., Mordekar, S.R., \& Seal, A. (2016). Fifteen minute consultation: Tics and Tourette syndrome. Archives of Disease in Childhood: Education and Practice Edition, 101, 87-94. 
- Pappert, E.J., Goetz, C.G., Louis, E.D., Blasucci, L., \& Leurgans, S. (2003). Objective assessments of longitudinal outcome in Gilles de la Tourette's syndrome. Neurology, 61, 936-940.

- Paschou, P. (2013). The genetic basis of Gilles de la Tourette syndrome. Neuroscience and Biobehavioral Reviews, 37, 1026-1039.

- Pauls, D.L., Fernandez, T.V., Mathews, C.A., State, M.W., \& Scharf, J.M. (2014). The inheritance of Tourette disorder: A review. Journal of Obsessive-Compulsive and Related Disorders, 3, 380-385.

- Piedad, J.C.P., \& Cavanna, A.E. (2016). Depression in Tourette syndrome: A controlled and comparison study. Journal of Neurological Sciences, 364, 128-132.

- Petruo, V., Bodmer, B., Bluschke, A., Münchau, A., Roessner, V., \& Beste, C. (2020). Comprehensive Behavioral Intervention for Tics reduces perception-action binding during inhibitory control in Gilles de la Tourette syndrome. Scientific Reports, 10, 1174.

- Petruo, V., Bodmer, B., Brandt, V.C., Baumung, L., Roessner, V., Münchau, A., \& Beste, C. (2019). Altered perception-action binding modulates inhibitory control in Gilles de la Tourette syndrome. Journal of Child Psychology and Psychiatry, 60, 953962.

- Pringsheim, T., Ho, J., Sarna, J.R., Hammer, T., \& Patten, S. (2017) Feasibility and relevance of antipsychotic safety monitoring in children with Tourette syndrome: A prospective longitudinal study. Journal of Clinical Psychopharmacology, 37, 498-504.

- Pringsheim, T., Holler-Managan, Y., Okun, M.S., Jankovic, J., Piacentini, J., Cavanna, A.E., ..., Oskoui, M. (2019a). Comprehensive systematic review summary: Treatment of tics in people with Tourette syndrome and chronic tic disorders. Neurology, 92, 907915. 
- Pringsheim, T., Okun, M.S., Müller-Vahl, K., Martino, D., Jankovic, J., Cavanna, A.E., ..., Piacentini, J. (2019b). Practice guideline recommendations summary: Treatment of tics in people with Tourette syndrome and chronic tic disorders. Neurology, 92, 896906.

- Robertson, M.M., Eapen, V., Singer, H.S., Martino, D., Scharf, J.M., Paschou, P., ..., Leckman, J.F. (2017). Gilles de la Tourette syndrome. Nature Reviews Disease Primers, 3, 16097.

- Scharf, J.M., Miller, L.L., Gauvin, C.A., Alabiso, J., Mathews, C.A., \& Ben-Shlomo, Y. (2015). Population prevalence of Tourette syndrome: A systematic review and metaanalysis. Movement Disorders, 30, 221-228.

- Singer, H.S. (2016). Habitual and goal-directed behaviours and Tourette syndrome. Brain, 139, 312-316.

- Termine, C., Luoni, C., Fontolan, S., Selvini, C., Perego, L., Pavone, F., ..., Cavanna AE. (2016). Impact of co-morbid attention-deficit and hyperactivity disorder on cognitive function in male children with Tourette syndrome: A controlled study. Psychiatry Research, 243, 263-267.

- Trillini, M.O., \& Müller-Vahl, K.R. (2015). Patients with Gilles de la Tourette syndrome have widespread personality differences. Psychiatry Research, 228, 765-773.

- Willsey, A.J., Fernandez, T.V., Yu, D., King, R.A., Dietrich, A., Xing, J., ..., Heiman, G.A. (2017). De novo coding variants are strongly associated with Tourette disorder. Neuron, 94, 486-499.

- Yang, J., Hirsch, L., Martino, D., Jette, N., Roberts, J., \& Pringsheim, T. (2016). The prevalence of diagnosed Tourette syndrome in Canada: A national population-based study. Movement Disorders, 31, 1658-1663. 
- Yaniv, A., Benaroya-Milshtein, N., Steinberg, T., Ruhrrman, D., Apter, A., \& Lavidor, M. (2017). Specific executive control impairments in Tourette syndrome: The role of response inhibition. Research in Developmental Disabilities, 61, 1-10. 


\section{TABLES}

Table 1. Key concepts in Tourette syndrome (in alphabetical order).

\begin{tabular}{|c|c|}
\hline Concept & Definition \\
\hline $\begin{array}{l}\text { Attention-deficit and } \\
\text { hyperactivity disorder } \\
\text { (ADHD) }\end{array}$ & $\begin{array}{l}\text { Psychiatric condition characterised by a persistent pattern of inattention and/or } \\
\text { hyperactivity-impulsivity that interferes with functioning or development since } \\
\text { childhood (before the age of } 12 \text { ). ADHD is the most common behavioural co- } \\
\text { morbidity in young patients with TS. }\end{array}$ \\
\hline $\begin{array}{l}\text { Behavioural } \\
\text { neurology }\end{array}$ & $\begin{array}{l}\text { Clinical discipline focusing on the assessment and management of the clinical } \\
\text { implications of behavioural symptoms caused by underlying brain pathologies. }\end{array}$ \\
\hline Coprolalia & Complex vocal tic consisting in involuntary swearing. \\
\hline Copropraxia & $\begin{array}{l}\text { Complex motor tic consisting in the involuntary production of obscene } \\
\text { gestures). }\end{array}$ \\
\hline Echolalia & Complex vocal tic consisting in the repetition of other people's words. \\
\hline Echopraxia & Complex motor tic consisting in the imitation of other people's movements. \\
\hline Impulsivity & $\begin{array}{l}\text { Behavioural pattern characterised by uncontrolled anger and temper tantrums } \\
\text { described as being 'out of character' and acted out 'in the heat of the moment' } \\
\text { and characteristically followed by feelings of regret. The clinical presentation of } \\
\text { impulsivity in patients with TS is different from the symptoms of impulse control } \\
\text { disorder reported in the context of other neurological disorders, such as } \\
\text { Parkinson disease (patients receiving dopamine replacement therapy engaging } \\
\text { in reward-seeking behaviours). }\end{array}$ \\
\hline $\begin{array}{l}\text { Obsessive- } \\
\text { compulsive disorder } \\
\text { (OCD) }\end{array}$ & $\begin{array}{l}\text { Psychiatric condition characterised by the presence of anxiety-led, recurrent } \\
\text { thoughts (obsessions) and/or repetitive behaviours (compulsions), which are } \\
\text { time-consuming (occupying at least one hour daily on average) and/or cause } \\
\text { significant clinical distress or functional impairment. OCD symptoms typically } \\
\text { peak in severity later than tics, toward the end of the first decade, and are the } \\
\text { second most common behavioural co-morbidity in patients with TS across the } \\
\text { lifespan. }\end{array}$ \\
\hline Palilalia & $\begin{array}{l}\text { Complex vocal tic consisting in the repetition of own words, often for a set } \\
\text { number of times or until the words sound 'just right'. }\end{array}$ \\
\hline Palipraxia & $\begin{array}{l}\text { Complex motor tic consisting in the repetition of own movements, often for a } \\
\text { set number of times or until the movement feels 'just right'. }\end{array}$ \\
\hline Premonitory urge & $\begin{array}{l}\text { Widespread or localised distressing physical sensation leading to and } \\
\text { temporarily alleviated by tic expression. }\end{array}$ \\
\hline Social cognition & $\begin{array}{l}\text { Area of psychology that focuses on the role that cognitive processes play in } \\
\text { social interactions: how people process, store, and apply information about } \\
\text { other people and social situations. }\end{array}$ \\
\hline Tic & $\begin{array}{l}\text { Sudden, rapid, recurrent, nonrhythmic movement or vocalisation, usually } \\
\text { expressed in response to a sensory urge (premonitory urge). }\end{array}$ \\
\hline Tic disorders & $\begin{array}{l}\text { Neurodevelopmental disorders characterised by the transient or chronic } \\
\text { presence of motor tics and/or vocal tics. }\end{array}$ \\
\hline Tic-related OCD & $\begin{array}{l}\text { Subtype of OCD reported by patients with a current or past history of a tic } \\
\text { disorder, characterised by an earlier age at onset compared to primary OCD } \\
\text { and a male predominance that is typical of tic disorders. In tic-related OCD } \\
\text { there seems to be a higher frequency of aggressive, sexual, and symmetry- } \\
\text { related obsessions, as well as of 'just right' phenomena and counting, ordering, } \\
\text { evening-up, and touching compulsions, compared to primary OCD. Tic-related } \\
\text { OCD is the most common behavioural co-morbidity in adult patients with TS. }\end{array}$ \\
\hline Tourette syndrome & $\begin{array}{l}\text { Complex tic disorder characterised by the chronic presence of both motor tics } \\
\text { (at least two) and vocal tics (at least one), with onset before the age of } 18 \text {. }\end{array}$ \\
\hline
\end{tabular}


Table 2. Examples of commonly reported motor and vocal tics.

\begin{tabular}{|c|c|}
\hline Tics & Examples \\
\hline Simple motor tics & $\begin{array}{l}\text { abdominal contractions } \\
\text { eye blinking } \\
\text { facial grimacing } \\
\text { mouth opening } \\
\text { neck stretching } \\
\text { shoulder shrugging }\end{array}$ \\
\hline Simple vocal tics & $\begin{array}{l}\text { coughing } \\
\text { grunting } \\
\text { humming } \\
\text { sniffing } \\
\text { snorting } \\
\text { throat clearing }\end{array}$ \\
\hline Complex motor tics & $\begin{array}{l}\text { copropraxia } \\
\text { echopraxia } \\
\text { forced touching } \\
\text { hitting } \\
\text { jumping } \\
\text { palipraxia }\end{array}$ \\
\hline Complex vocal tics & $\begin{array}{l}\text { barely audible muttering } \\
\text { coprolalia } \\
\text { echolalia } \\
\text { palilalia } \\
\text { random words } \\
\text { talking to self }\end{array}$ \\
\hline
\end{tabular}


Table 3. Summary of key diagnostic features of the main tic disorders (onset before 18 years).

\begin{tabular}{|l|c|c|c|c|}
\hline Tic disorder & $\begin{array}{c}\text { Number of motor } \\
\text { tics }\end{array}$ & $\begin{array}{c}\text { Number of vocal } \\
\text { tics }\end{array}$ & $\begin{array}{c}\text { Chronic tics } \\
\text { or OCD* }\end{array}$ \\
\hline $\begin{array}{l}\text { Tourette } \\
\text { syndrome }\end{array}$ & $2+$ & $1+$ & yes & $\begin{array}{c}\text { very frequent } \\
(72 \%)\end{array}$ \\
\hline $\begin{array}{l}\text { Persistent vocal tic } \\
\text { disorder }\end{array}$ & 0 & $1+$ & yes & frequent \\
Persistent motor & $1+$ & 0 & yes & occasional \\
tic disorder & & & & $(12 \%)$ \\
\hline $\begin{array}{l}\text { Provisional tic } \\
\text { disorder* }\end{array}$ & $0 / 1+$ & $0 / 1+$ & no & rare \\
\hline
\end{tabular}

${ }^{*}$ Community data (school-age children) from Khalifa and von Knorring (2006).

${ }^{* *}$ Patients with provisional tic disorder present with at least one motor and/or vocal tic.

Abbreviations: ADHD, attention-deficit and hyperactivity disorder; $O C D$, obsessivecompulsive disorder. 
Table 4. Clinical features of Tourette syndrome explicitly accounted for by two neurocognitive models: the altered perception-action binding theory and the social decision-making dysfunction theory.

\begin{tabular}{|l|c|c|}
\hline \multicolumn{1}{|c|}{ Feature of Tourette syndrome } & $\begin{array}{c}\text { Altered perception-action } \\
\text { binding theory }\end{array}$ & $\begin{array}{c}\text { Social decision-making } \\
\text { dysfunction theory }\end{array}$ \\
\hline Coprophenomena & Yes & Yes \\
\hline Distribution of motor tics & Yes & Yes \\
\hline Echophenomena & Yes & Yes \\
\hline Hyper-mentalising tendency & No \\
\hline Hypersensitivity to sensory stimuli & Yes \\
\hline Impulsivity & Yes & No \\
\hline Involvement of the basal ganglia & Yes \\
\hline Male predominance & No & Yes \\
\hline $\begin{array}{l}\text { Modulation of tic expression } \\
\text { attentional loading }\end{array}$ & Yes & Yes \\
\hline Natural history of tics & Yes & Yes \\
\hline Presence and nature of vocal tics & Yes & Yes \\
\hline Sensory urges & Yes & No \\
\hline Stereotyped nature of tics & & \\
\hline
\end{tabular}

